NIST

PUBLICATIONS

\section{Electronics and Electrical Engineering Laboratory}

\section{Technical Publication Announcements}

Covering Laboratory Programs, January to March 1991, with 1991 EEEL Events Calendar
U.S. DEPARTMENT OF COMMERCE National Institute of Standards and Technology Electronics and Electrical Engineering Laboratory Semiconductor Electronics Division Gaithersburg, MD 20899

September 1991

\title{
28
}

QC 



\section{NISTIR 4675}

\section{Electronics and Electrical Engineering Laboratory}

\section{Technical \\ Publication Announcements}

Covering Laboratory Programs, January to March 1991, with 1991 EEEL Events Calendar
U.S. DEPARTMENT OF COMMERCE National Institute of Standards and Technology Electronics and Electrical Engineering Laboratory Semiconductor Electronics Division Gaithersburg, MD 20899

September 1991

\section{8}

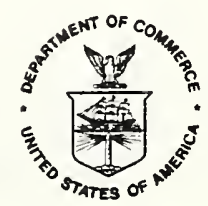




\section{INTRODUCTION TO THE EEEL TECHNICAL PUBLICATION ANNOUNCEMENTS}

This is the twenty-eighth issue of a quarterly publication providing information on the technical work of the National Institute of Standards and Technology Electronics and Electrical Engineering Laboratory (EEEL) (until February 1991, the Center for Electronics and Electrical Engineering). This issue of the EEEL Technical Publication Announcements covers the first quarter of calendar year 1991.

Organization of Bulletin: This issue contains citations and abstracts for Laboratory publications published in the quarter. Entries are arranged by technical topic as identified in the Table of Contents and alphabetically by first author within each topic. Following each abstract is the name and telephone number of the individual to contact for more information on the topic (usually the first author). This issue also includes a calendar of Laboratory conferences and workshops planned for calendar year 1991 and a list of sponsors of the work.

Electronics and Electrical Engineering Laboratory: EEEL programs provide national reference standards, measurement methods, supporting theory and data, and traceability to national standards. The metrological products of these programs aid economic growth by promoting equity and efficiency in the marketplace, by removing metrological barriers to improved productivity and innovation, by increasing U.S. competitiveness in international markets through facilitation of compliance with international agreements, and by providing technical bases for the development of voluntary standards for domestic and international trade. These metrological products also aid in the development of rational regulatory policy and promote efficient functioning of technical programs of the Government.

The work of the Laboratory is conducted by four technical research Divisions: the Semiconductor Electronics and the Electricity Divisions in Gaithersburg, Md., and the Electromagnetic Fields and Electromagnetic Technology Divisions in Boulder, Colo. In 1991, the Office of Law Enforcement Standards, formerly the Law Enforcement Standards Laboratory, was transferred to EEEL. This Office conducts research and provides technical services to the U.S. Department of Justice, State and local governments, and other agencies in support of law enforcement activities. In addition, the Office of Microelectronics Programs (OMP) was established in EEEL to coordinate the growing number of semiconductor-related research activities at NIST. Reports of work funded through the OMP are included under the heading "Semiconductor Microelectronics."

Key contacts in the Laboratory are given on the back cover; readers are encouraged to contact any of these individuals for further information. To request a subscription or for more information on the Bulletin, write to EEEL Technical Progress Bulletin, National Institute of Standards and Technology, Metrology Building, Room B-358, Gaithersburg, MD 20899 or call (301) 975-2220.

Laboratory Sponsors: The Laboratory Programs are sponsored by the National Institute of Standards and Technology and a number of other organizations, in both the Federal and private sectors; these are identified on page 15 .

Note on Publication Lists: Publication lists covering the work of each division are guides to earlier as well as recent work. These lists are revised and reissued on an approximately annual basis and are available from the originating division. The current set is identified in the Additional Information section, page 13. 


\section{TABLE OF CONTENTS}

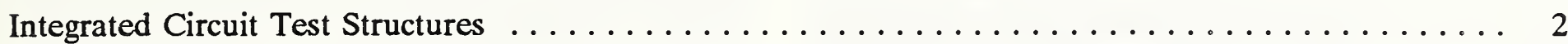

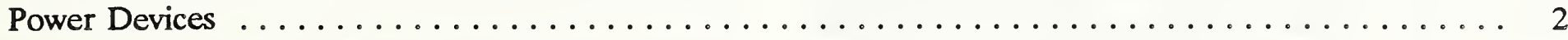

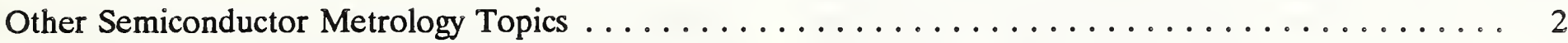

SIGNAL ACQUISITION, PROCESSING, \& TRANSMISSION $\ldots \ldots \ldots \ldots \ldots \ldots \ldots \ldots \ldots$

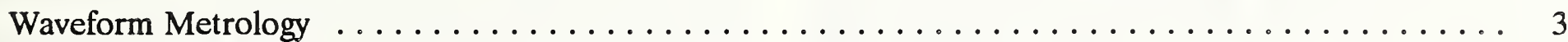

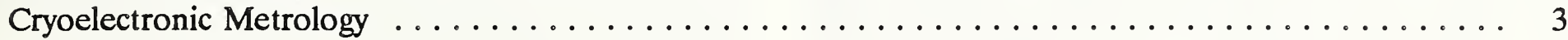

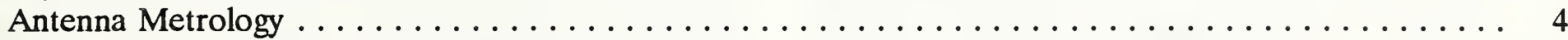

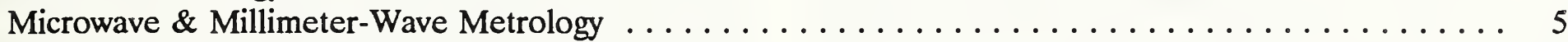

Electromagnetic Properties $\ldots \ldots \ldots \ldots \ldots \ldots \ldots \ldots \ldots \ldots \ldots \ldots \ldots \ldots \ldots \ldots \ldots \ldots \ldots \ldots$

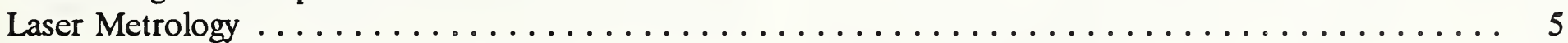

Optical Fiber Metrology $\ldots \ldots \ldots \ldots \ldots \ldots \ldots \ldots \ldots \ldots \ldots \ldots \ldots \ldots \ldots$

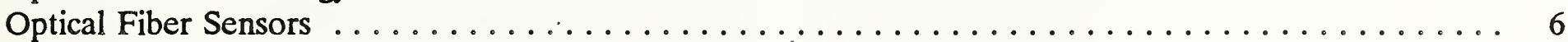

Electro-Optic Metrology $\ldots \ldots \ldots \ldots \ldots \ldots \ldots \ldots \ldots \ldots \ldots \ldots \ldots \ldots \ldots \ldots \ldots$

ELECTRICAL SYSTEMS $\ldots \ldots \ldots \ldots \ldots \ldots \ldots \ldots \ldots \ldots \ldots \ldots \ldots \ldots \ldots \ldots$

Power Systems $\ldots \ldots \ldots \ldots \ldots \ldots \ldots \ldots \ldots \ldots \ldots \ldots \ldots \ldots \ldots \ldots \ldots \ldots \ldots \ldots \ldots$

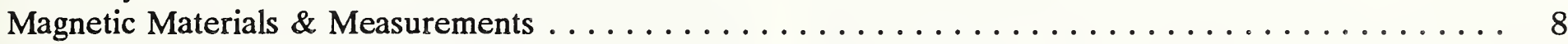

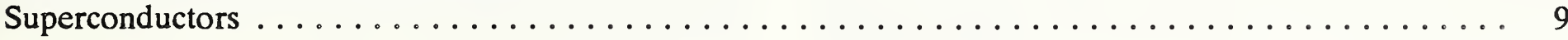

ELECTROMAGNETIC INTERFERENCE $\ldots \ldots \ldots \ldots \ldots \ldots \ldots \ldots \ldots \ldots \ldots \ldots \ldots \ldots$

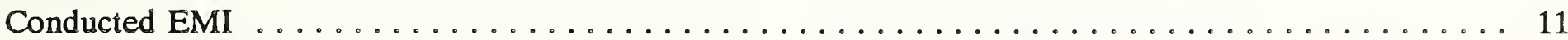

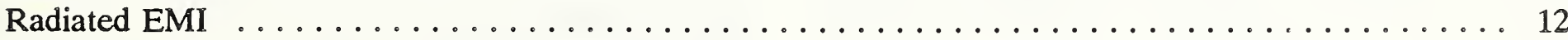

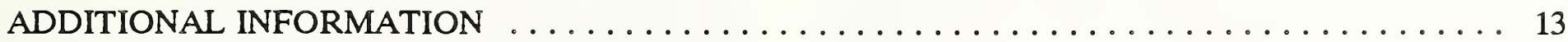

1991 EEEL CALENDAR . . . . . . . . . . . . . . . . . . . . . . . . . . . 14

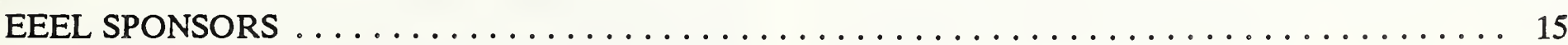

KEY CONTACTS IN LABORATORY, LABORATORY ORGANIZATION . . . . . . . . . b back cover 


\section{SEMICONDUCTOR MICROELECTRONICS}

\section{Integrated Circuit Test Structures}

Khera, D., Linholm, L.W., Allen, R.A., Cresswell, M.W., Tyree, V.C., Hansford, W., and Pina, C., Knowledge Verification of Machine-Learning Procedures Based on Test Structure Measurements, Proceedings of the International Conference on Microelectronic Test Structures, Koyto, Japan, March 18-20, 1991, pp. 145-149 (1991).

This paper describes an approach for evaluating and refining the rules, based on test structure measurements, to be entered into the knowledge base of an expert system. The objective is to qualify the performance of rules determined by a machinelearning classification application with the best knowledge available from the human experts. The technique combines a machine-learning approach with the traditional heuristic-based development of an expert system. Strengths and weaknesses of the individual techniques are compared.

[Contact: Raj Khera, (301) 975-2240]

\section{$\underline{\text { Power Devices }}$}

Gao, G., Fan, Z., Blackburn, D.L., Unlu, M.S., Chen, J., Adomi, K., and Morkoc, H., Uniform Junction Temperature AlGaAs/GaAs Power Heterojunction Bipolar Transistors on Silicon Substrates, Applied Physics Letters, Vol. 58, No., 10, pp. 1068-1070 (11 March 1991).

AlGaAs/GaAs power heterojunction bipolar transistors on $\mathrm{Si}$ substrates exhibiting uniform junction temperature distribution are reported. Owing to a unique device design, the temperature spread across the entire device area is about $1{ }^{\circ} \mathrm{C}$. The device exhibits a common emitter current gain of 20 , a maximum collector current of $0.6 \mathrm{~A}$, and a collector base junction breakdown voltage of $25 \mathrm{~V}$.

[Contact: David L. Blackburn, (301) 975-2068]

Gao, G-B., Unlu, M.S., Morkoc, H., and Blackburn, D.L., Emitter Ballasting Resistor Design for and Current Handling Capability of AIGaAs/GaAs Power Heterojunction Bipolar Transistors, IEEE Transactions on Electron Devices, Vol. 38, No. 2, pp. 185-196 (February 1991).
A systematic investigation of the emitter ballasting resistor for power Heterojunction Bipolar Transistors (HBTs) is presented. The current handling capability of power HBTs is found to improve with ballasting resistance. An equation for the optimal ballasting resistance is presented, where the effects of thermal conductivity of the substrate material and the temperature coefficient of the ballasting resistor are taken into account. Current levels of 400 to $800 \mathrm{~mA} / \mathrm{mm}$ of emitter periphery at case temperatures of 25 to $-80^{\circ} \mathrm{C}$ for power AlGaAs/GaAs HBTs have been obtained using an on-chip lightly-doped $\mathrm{GaAs}$ emitter ballasting resistor.

Device temperature has been measured using both an infrared micro-radiometer and temperature-sensitive electrical parameters. Steady-state and transient thermal modeling were also performed. Although the measured temperature is spatially nonuniform, the modeling results show that such nonuniformities would occur for a uniform current distribution, as would be expected for an HBT with emitter ballasting resistors. [Contact: David L. Blackburn, (301) 975-2068]

\section{Other Semiconductor Metrology Topics}

Parameswaran, M., Robinson, A.M., Blackburn, D.L, Gaitan, M., and Geist, J., Micromachined Thermal Radiation Emitter from a Commercial CMOS Process [original title: Micromachined Thermal and Visible Radiation Source Using a Commercial CMOS Process], IEEE Electron Device Letters, Vol. 12, No. 2, pp. 57-59 (February 1991).

Fabrication of a thermally isolated micromechanical structure capable of generating thermal radiation for dynamic thermal scene simulation (DTSS) is described. Complete compatibility with a commercial CMOS process is achieved through design of a novel, but acceptable, layout for implementation by the CMOS foundry using its regular process sequence. Following commercial production and delivery of the CMOS chips, a single maskless etch in an aqueous ethylenediamine-pyrocatechol mixture is performed to realize the micromechanical structures. The resulting structures are suspended plates consisting of polysilicon resistors encapsulated in the field and CVD oxides available in the CMOS process. The plates are suspended by aluminum heater leads that are also encapsulated in the field and CVD oxides. Studies of the suitability of these structures for DTSS have been 
initiated, and early favorable results are reported.

[Contact: Jon Geist, (301) 975-2066]

\section{SIGNAL ACQUISITION, PROCESSING, \& TRANSMISSION}

\section{Waveform Metrology}

Gans, W.L., Dynamic Calibration of Waveform Recorders and Oscilloscopes Using Pulse Standards, IEEE Transactions on Instrumentation and Measurement, Vol. 39, No. 6, pp. 952-957 (December 1990).

The purpose of this paper is to convince the reader of two key points. First, virtually no one calibrates oscilloscopes or waveform recorders properly and completely at present. Second, in most cases, the tools are now available to perform these complete and proper calibrations when the application requires it. After a brief introduction describing the current methods used to calibrate oscilloscopes, the problems associated with oscilloscope vertical channel bandwidth testing are discussed and illustrated. Then, a solution is described that involves using pulse signals and a NIST-developed deconvolution algorithm. Finally, an example of the calibration of a $20-\mathrm{GHz}$ sampling oscilloscope is presented.

[Contact: William L. Gans, (303) 497-3538]

Souders, T.M., and Stenbakken, G.N., Cutting the High Cost of Testing [original title: New Solutions for the High Cost of Testing], IEEE Spectrum, Energy Outlook, Confusion and Indecision, pp. 48-51 (March 1991).

An approach for reducing the test time for analog and mixed-signal devices is presented. This approach relies upon an error model for the device type. The paper describes how the error model can be developed from the physical description of the device or from empirical data taken on representative devices. Use of the error model to select an optimum set of test points and to predict the errors at all test points is described. Finally, the results of applying the method to a 13-bit analog-to-digital converter design is presented.

[Contact: T. Michael Souders, (301) 975-2406]

\section{Cryoelectronic Metrology}

Beall, J.A., Cromar, M.W., Harvey, T.E., Johansson,
M.E., Ono, R.H., Reintsema, C.D., Rudman, D.A, Asher, S.E., Nelson, A.J., and Swartzlander, A.B., $\mathrm{YBA}_{2} \mathrm{CU}_{3} \mathbf{O}_{7-\delta}$ /Insulator Multi-Layers for Crossover Fabrication, IEEE Transactions on Magnetics, Vol. 27, No. 2, pp. 1596-1599 (March 1991).

The development of thin-film dielectrics compatible with epitaxial growth of $\mathrm{YBa}_{2} \mathrm{Cu}_{3} \mathrm{O}_{7-\delta}$ (YBCO) is crucial to the fabrication of multilayer device and circuit structures. We have investigated the $\mathrm{YBCO} / \mathrm{SrTi0}_{3}$ (STO) system by fabricating YBCO/STO bilayers and simple YBCO/STO/YBCO crossover structures. The thin films were deposited in situ by pulsed laser deposition and analyzed using X-ray diffraction and scanning electron microscopy. The film interfaces were characterized by secondary-ion-mass spectroscopy depth profiling. We have developed photolithographic and wet-etching processes for patterning the crossovers which are compatible with these materials. The crossover structures were characterized by resistance and insulator pinhole density as well as the superconducting properties of the patterned top and bottom YBCO electrodes (critical temperature, $\mathrm{T}_{\mathrm{c}}$ and critical current density, $\mathrm{J}_{c}$ ). Using $\mathrm{SrTiO}_{3}$ as the insulating layer, we have made crossovers with good isolation between layers $\left(>100 \mathrm{M} \Omega\right.$ ) and high $\mathrm{J}_{\mathrm{c}}$ even in the top electrode $\left(\mathrm{J}_{\mathrm{c}}(76) \mathrm{K}>10^{5} \mathrm{~A} / \mathrm{cm}^{2}\right)$.

[Contact: James A. Beall, (303) 497-5989]

Cunningham, C.E., Park, G.S., Cabrera, B., and Huber, M. E., Correlation of Flux States Generated by Optical Switching of a Superconducting Circuit, Physica B, Vols. 165 \& 166, pp. 113-114 (Elsevier Science Publishers B.V., North-Holland, 1990).

We used an optically tripped superconducting switch to change the quantum flux state of a superconducting circuit. We varied the optical pulse length over six decades between $6 \mathrm{~ns}$ and $10 \mathrm{~ms}$ and measured the correlation between successive flux states at each pulse length. The correlations fit a simple Fokker-Planck conditional probability model.

[Contact: Martin E. Huber, (303) 497-5423]

Moreland, J., Ekin, J.W., and Larson, T., Prospects for High Temperature Superconductor-Semiconductor Contacts, New Technology in Electronic Packaging (Proceedings of the ASM International 3rd Electronic Materials and Processing Congress, San 
Francisco, California, August 20-23, 1990), pp. 195 201 (1991).

Development of high-temperature superconductorsemiconductor contacts with very low contact resistivities is required for microelectronic applications such as circuit interconnects or superconductorsemiconductor-superconductor (S/Semi/S) proximity effect devices. Several thin-film deposition methods have been developed for forming very low resistance contacts to high-temperature superconductors. For example, we have measured contact resistivities as low as $10^{-10} \Omega-\mathrm{cm}^{2}$ for annealed $\mathrm{Ag}$ films on sintered $\mathrm{YBa}_{2} \mathrm{Cu}_{3} \mathrm{O}_{7-\delta}$ samples. Such a contact could potentially be part of a superconductor-semiconductor contact that relies on an intervening normal metal, spanning superconductor and semiconductor interfaces. Presently, we are surveying materials commonly used to make ohmic contacts to $\mathrm{Si}$ and $\mathrm{GaAs}$ for their compatibility with high-temperature superconductors. Prime material characteristics necessary for potential contact structures are 1) low chemical reactivity of the intervening materials with high-temperature superconductors; 2) limited interdiffusion of multilayer constituents; and 3) stable, low contact resistivity, ohmic I-V characteristics.

[Contact: John Moreland, (303) 497-3641]

Peterson, R.L., Sidelobe Suppression in Small Josephson Junctions, Cryogenics, Vol. 31, pp. 132135 (February 1991).

Many applications of Josephson junctions require that the sidelobes of the critical-current patterns as a function of magnetic field be as small as possible. The first sidelobes in small Josephson junctions are shown here to be capable of suppression below the $1 \%$ level by appropriate choice of junction geometry. For a wide variety of shaped junctions, the diffraction patterns can be expressed by simple formulas. For applications requiring long junctions, an analysis based on small junctions of the same geometry is a practical starting point.

[Contact: Robert L. Peterson, (303) 497-3750]

\section{Antenna Metrology}

Camell, D.G., Larsen, E.B., Cruz, J.E., and Hill, D.A. NIST Calibration Procedure for Vertically Polarized Monopole Antennas, $30 \mathrm{kHz}$ to $300 \mathrm{MHz}$, NIST Technical Note 1347 (January 1991).
This report describes the theoretical basis and test procedure for vertically polarized monopole antenna calibrations at the National Institute of Standards and Technology (NIST). The standard field method applies the theoretical equations of a vertical monopole antenna to calculate the vertical electric field. This method is used at the NIST open-field site in the frequency range of $30 \mathrm{kHz}$ to $300 \mathrm{MHz}$. The uncertainty in the antenna factor of the antenna under test (AUT) is now $\pm 1 \mathrm{~dB}$.

[Contact: Dennis G. Camell, (303) 497-3214]

Muth, L.A., and Lewis, R.L., A General Technique to Correct Probe Position Errors in Planar Near-Field Measurements to Arbitrary Accuracy [original title: An Iterative Technique to Correct Probe Position Errors in Planar Near-Field Measurements], IEEE Transactions on Antennas and Propagation, Vol. 38, No. 12, pp. 1925-1932 (December 1990).

We present a general theoretical procedure to remove known probe position errors when planar near-field data are transformed to the far field. We represent the measured data as a Taylor series, whose terms contain the error function and the ideal spectrum of the antenna. This representation is then assumed to be an actual near field existing on an error-free, regularly spaced, two-dimensional scan plane. Then by inverting the Taylor series, we obtain the ideal spectrum in terms of the measured data and the position errors. The solution is given in terms of an error operator that acts on the measured data (incorporating measurement errors). This error operator is the Taylor series without the zeroth-order term. The nth-order approximation to the ideal near field of the antenna can be explicitly constructed by inspection of the structure of the error operator. Since we have an infinite series of a differential operator, the question of convergence is addressed. Computer simulations using periodic error functions show that we are dealing with a convergent series, and the error correction technique is seen to be highly successful. This is demonstrated for a triple periodic error function. The root-mean-square values of the far fields as functions of the radius in $\mathrm{k}$ (wavenumber) space are calculated and compared for the error-free, error-contaminated, and error-corrected far fields. Appropriate graphical representation of the error fields, the error-contaminated, and error-free fields are presented to enhance understanding of the results. [Contact: Lorant A. Muth, (303) 497-3603] 


\section{Microwave \& Millimeter-Wave Metrology}

Daywitt, W.C., Determining Adapter Efficiency by Envelope Averaging Swept Frequency Reflection Data [original title: Determining Adapter Efficiency from Swept Frequency Reflection Data], IEEE Transactions on Microwave Theory and Techniques, Vol. 38, No. 11, pp. 1748-1752 (November 1990).

A simple automated network analyzer (ANA) swept frequency technique for measuring adapter efficiency is described. Calculations show that errors arising from theoretical approximations (excluding ANA measurement errors) are around $0.004 \mathrm{~dB}$ for a common WR 42 waveguide-to-coaxial adapter.

[Contact: William C. Daywitt, (303) 497-3720]

Sherwood, G.V., Air Gage Size Measurement of Microwave Standards, Proceedings of the 1991 Measurement Science Conference, Anaheim, California, January 31-February 1, 1991. pp. 1-10 (1991).

Size measurement of waveguides and coaxial transmission line standards has been performed at the National Institute of Standards and Technology (NIST) for many years. Recently, the air gaging systems used to perform these measurements have been enhanced using digital data acquisition methods to facilitate computer analysis. Initial experiments were performed using air gaging probes on a coordinate measuring machine to correlate linear position with size attributes. Related geometric and dimensional characteristics that contribute to the uncertainty of measurement were also studied. Alternative assessment methods have been utilized to provide a more complete characterization of these features and complement air gage size measurements using a systems approach. This article is a report of these developments at NIST.

[Contact: Glenn V. Sherwood, (303) 497-3939]

Williams, D.F., Marks, R.B., and Phillips, K.R., Translate LRL and LRM Calibrations [original title: Translating Between LRL and LRM Calibrations], Microwaves \& RF, Vol. 30, No. 2, pp. 78ff (February 1991).

The Line-Reflect-Match calibration technique (LRM) is reviewed. Unless the match standard is perfect, calibration using the most common form of LRM differs from that of the Line-Reflect-Line technique (LRL). We present an explicit transformation which relates the two calibrations.

[Contact: Dylan F. Williams, (303) 497-3138]

\section{Electromagnetic Properties}

van Roggen, A., Yuwono, L., Zhou, H., Meijer, P.H.E., and Kopanski, J.J., Permittivity Measurements on Molecular-Sized Samples, Extended Abstract, presented as poster only at the IEEE Conference on Electrical Insulation and Dielectric Phenomena (CEIDP), Pocono Manor, Pennsylvania, October 29-November 1, 1990, Paper 7-14, pp. 385-390 (January 1991).

A new laboratory on Molecular Electronics has been started at the Physics Department of the Catholic University of America. In our efforts to make organic bistable devices, one of the research functions of this laboratory is to measure the electrical properties of materials and active devices made with molecular (mainly organic) materials. The size of material samples, and the specimens used for measurement, is exceedingly small, typically layers with a thickness of the order of $100 \mathrm{~nm}$. Consequently, the setups used for normal dielectric and conductivity measurements ( $\geq 10 \mathrm{~mm}$ electrode size) cannot be used, and special cells and instrumentation have to be developed.

[Contact: Joseph J. Kopanski, (301) 975-2089]

\section{Laser Metrology}

Paulter, N.G., Jr., and Majumdar, A.K., A New Triple Correlation Technique for Measuring Ultrashort Laser Pulses [original title: A New Triple Correlation Technique for the Measurement of Ultrashort Laser Pulses], Review of Scientific Instruments, Vol. 62, No. 3, pp. 567-578 (March 1991).

A new triple correlation technique for the measurement of the complete intensity profile of ultrashort optical pulses is described. In general, the triple correlation technique preserves the phase information of the input pulse so that a reconstruction of the triple-correlated signal will provide a unique reconstruction of the input. The new technique described here uses two second-order, nonlinear optical interactions for the generation of the triple correlation signal. A derivation of the measured triple 
correlation signal and the pulse reconstruction is given. The effects of noise on the measured signal are also examined.

[Contact: Nicholas G. Paulter, Jr., (303) 497-3400]

Paulter, N.G., Jr., and Majumdar, A.K, A New Triple Correlator Design for the Measurement of Ultrashort Laser Pulses [original title: A New Proposed Triple Correlator for the Measurement of Ultrashort Laser Pulses], Optics Communications, Vol. 81, Nos. 1,2, pp. 95-100 (1 February 1991).

A measurement device, a triple correlator, is proposed for the characterization of ultrashort optical pulses. The proposed triple correlator uses two consecutive nonlinear optical interactions, a sum frequency generation followed by a difference frequency generation, to produce a triple correlation output at the same optical frequencies as the input pulse. Phase matching for the triple correlator is greatly simplified by using the given design. The operation of the triple correlator is described and examples of expected output signals are given. The reconstructed optical pulse is quite insensitive to noise, as shown by computer simulations.

[Contact: Nicholas G. Paulter, Jr., (303) 497-3400]

\section{Optical Fiber Metrology}

Gilbert, S.L., Frequency Stabilization of an ErbiumDoped Fiber Laser: A Potential Wavelength Standard for Optical Communications, Technical Digest, 1991 Optical Fiber Communication Conference, San Diego, California, February 18-22, 1991 , p. 85.

Wavelength standards in the $1.5-\mu \mathrm{m}$ range are important for many of the proposed optical communication schemes involving frequency-division multiplexing and coherent heterodyne detection. Fiber lasers are attractive candidates for use in such wavelength standards because of their potential for narrow-linewidth operation. Previous studies of singlelongitudinal-mode Er-doped fiber lasers have reported narrow-linewidth operation, but a complete analysis of the frequency noise characteristics has not been carried out. I have found that fluctuations in fiber laser frequency are small and are dominated by lowfrequency $(\leq 600-\mathrm{Hz})$ components arising from mechanical vibrations, thermal drift, and fluctuations of the pump laser intensity. This aspect makes fiber lasers particularly easy to stabilize by using an electronic servomechanism. In the apparatus two pieces of Er-doped fiber form a coupled-cavity system within a longer standing-wave cavity and a diffraction grating. The overlap of the transmission peaks of these cavities within the bandwidth of the 1200groove/mm grating selects a single longitudinal mode. Course tuning of the wavelength is accomplished by translating and tilting the grating with a piezoelectric transducer (PZT) and stretching the longer fiber with another PZT. The laser is tunable from $1.52 \mu \mathrm{m}$ to $1.58 \mu \mathrm{m}$ and has a threshold of $30 \mathrm{~mW}$ (pump power coupled into the fiber) and a peak slope efficiency of $10 \%$.

[Contact: Sarah L. Gilbert, (303) 497-3120]

\section{Gilbert, S.L., Frequency Stabilization of a Tunable}

Erbium-Doped Fiber Laser, Optics Letters, Vol. 16, No. 3, pp. 150-152 (February 1, 1991)。 [Summary paper on the same topic (Frequency Stabilization of an Erbium-Doped Fiber Laser: A Potential Wavelength Standard for Optical Communications) was given at the Conference on Optical Fiber Communications, San Diego, California, February 1822, 1991.]

A single-frequency erbium-doped fiber laser that is tunable from 1.52 to $1.58 \mu \mathrm{m}$ has been constructed. The laser linewidth was determined to be less than 1.6 $\mathrm{MHz}$ full width half maximum by observing the spectrum of the beat between the fiber laser and a 1.523- $\mu \mathrm{m}$ helium-neon laser. The frequency of the fiber laser was locked to several absorption lines of acetylene near $1.53 \mu \mathrm{m}$. This research demonstrates the inherent stability of fiber lasers and their potential for use in a wavelength standard for optical communications.

[Contact: Sarah L. Gilbert, (303) 497-3120]

\section{Optical Fiber Sensors}

Deeter, M.N., Rose, A.H., and Day, G.W., IronGarnet Magnetic Field Sensors with $100 \mathrm{pT} / \sqrt{\mathrm{Hz}}$ Noise-Equivalent Field, Proceedings of the Seventh Optical Fibre Sensors Conference, Sydney, New South Wales, Australia, December 2-6, 1990, pp. 341-344 (1991).

The sensitivity of Faraday-effect sensors incorporating diamagnetically-substituted yttrium iron garnet (YIG) is potentially much higher than of sensors employing 
pure YIG. Results of Faraday rotation linearity and sensitivity measurements are presented for galliumsubstituted YIG. At $500 \mathrm{~Hz}$, the noise-equivalent magnetic field is approximately $100 \mathrm{pT} / \sqrt{\mathrm{Hz}}$.

[Contact: Merritt N. Deeter, (303) 497-5400]

Tang, D., Rose, A.H., and Day, G.W., Optical Fiber Current Sensors with Temperature Stabilities Near the Material Limit, Proceedings of the Seventh Optical Fibre Sensors Conference, Sydney, New South Wales, Australia, December 2-6, 1990, unpaged, (1991).

We describe an optical fiber current sensor with a normalized temperature coefficient of $+8.4 \times 10^{-5} / \mathrm{K}$ over the range from -75 to $+145^{\circ} \mathrm{C}$. This is within $20 \%$ of the limit set by the temperature dependence of the Verdet constant measured in bulk silica. Packaging of the sensor coil degrades its stability, but a fully packaged coil with a stability of $+1.7 \times 10^{-4} / \mathrm{K}$ over the range from -30 to $+125^{\circ} \mathrm{C}$ has also been demonstrated.

[Contact: Allen H. Rose, (303) 497-5599]

Veeser, L.R., and Day, G.W., Faraday Effect Current Sensing Using a Sagnac Interferometer with a $3 \times 3$ Coupler, Proceedings of the Seventh Optical Fibre Sensors Conference, Sydney, New South Wales, Australia, December 2-6, 1990, pp. 325-328 (1991).

We demonstrate a fiber optic current sensor based on a Sagnac interferometer with a $3 \times 3$ fiber coupler. Compared to the more common Sagnac interferometer with a $2 \times 2$ coupler, this design offers the additional benefits of a greater response for small signals and the unambiguous interpretation of signals that exceed the period of the response function.

[Contact: Gordon W. Day, (303) 497-5204]

\section{Electro-Optic Metrology}

Goyal, I.C., Gallawa, R.L., and Ghatak, A.K., Methods of Analyzing Planar Optical Waveguides [original title: A New Method of Analyzing Planar Optical Waveguides], Optics Letters, Vol. 16, No. 1, pp. 3032 (January 1, 1991).

We present a new approximate solution of the scalarwave equation for planar optical waveguides with arbitrary refractive-index profiles. Test calculations are done for an index profile with a known solution.
The comparison demonstrates the accuracy of our method. The method may also be applied to circularly symmetric optical fibers.

[Contact: Robert L. Gallawa, (303) 497-3761]

Parameswaran, M., Robinson, A.M., Blackburn, D.L, Gaitan, M., and Geist, J., Micromachined Thermal Radiation Emitter from a Commercial CMOS Process [original title: Micromachined Thermal and Visible Radiation Source Using a Commercial CMOS Process], IEEE Electron Device Letters, Vol. 12, No. 2, pp. 57-59 (February 1991).

Fabrication of a thermally isolated micromechanical structure capable of generating thermal radiation for dynamic thermal scene simulation (DTSS) is described. Complete compatibility with a commercial CMOS process is achieved through design of a novel, but acceptable, layout for implementation by the CMOS foundry using its regular process sequence. Following commercial production and delivery of the CMOS chips, a single maskless etch in an aqueous ethylenediamine-pyrocatechol mixture is performed to realize the micromechanical structures. The resulting structures are suspended plates consisting of polysilicon resistors encapsulated in the field and CVD oxides available in the CMOS process. The plates are suspended by aluminum heater leads that are also encapsulated in the field and CVD oxides. Studies of the suitability of these structures for DTSS have been initiated, and early favorable results are reported.

[Contact: Jon Geist, (301) 975-2066]

Sanford, N.A., Malone, KJ., and Larson, D.R., Integrated-Optic Waveguide Glass Lasers, Technical Digest of the Optical Fiber Communication Conference, San Diego, California, February 18-22, 1991, p. 27 (1991).

Rare-earth-doped integrated-optic waveguide devices offer new miniaturized cw and pulsed lasers, amplifiers, and other active elements. Fabrication methods which use bulk glasses, as well as chemicalvapor deposition techniques, are being explored.

[Contact: Norman A. Sanford, (303) 497-5239]

Tu, Y., Goyal, I.C., and Gallawa, R.L., Analyzing Integrated Optical Waveguides: A Comparison of Two New Methods [original title: A Comparison of Two Recent Methods of Analyzing Integrated Optical Waveguides], Applied Optics, Vol. 29, No. 


\section{6, pp. 5313-5315 (20 December 1990).}

We present here a comparison of two recent methods (one of which is numeric, the other an approximate analytic method) of predicting waveguide parameters, each with a particular strength. Although the methods are quite general, we restrict attention to a onedimensional waveguide having an exponential profile with a known analytic solution to illustrate the strength of each of the two methods. We then use a quadratic (parabolic) profile that has no closed form analytic solution but is potentially useful inasmuch as it represents a profile which gives further insight into the strengths and weaknesses of the two present methods. This is the first comparison of these two new methods which we believe hold considerable promise for waveguide analysis. The purpose here is to prove the utility of the methods, that they might be used for more general profiles, for which parametric tendencies are now known.

Veasey, D.L., Larson, D.R., Phelan, R.J., Jr., and Batchman, T.E., Semiconductor Claddings on Glass Waveguides for Polarizers and Detectors, Optical Society of America 1990 Annual Meeting Technical Digest, Boston, Massachusetts, November 4-9, 1990, unpaged (1991).

TE and TM polarizers and polarization sensitive detectors were fabricated by cladding glass channel waveguides with hydrogenated amorphous silicon. Extinction ratios as high as $48 \mathrm{~dB}$ have been observed for the TE-pass device and up to $34 \mathrm{~dB}$ for the TMpass device.

[Contact: David L. Veasey, (303) 497-3439]

\section{ELECTRICAL SYSTEMS}

\section{Power Systems}

Fenimore, C.P., Jr., and FitzPatrick, G.J., Measurement Reliability: The Detection of Nonlinearities, Proceedings of the Space Nuclear Power Systems Eighth Symposium, Albuquerque, New Mexico, January 7-10, 1991, pp. 1113-1118 (1991).

The detection of a single measurement failure in a compound measurement system consisting of a voltage divider and a Kerr cell is demonstrated. The comparison of measurement devices based on distinct technologies is inherently robust; they may be expected to have distinct failure characteristics. The Kerr comparison is based on model fitting applied to numerically generated data and experimental, digitally recorded waveforms. The characteristic signatures of two measurement errors are found for a quadratic nonlinearity in the detector and for an overdriven photodetector. The length of the data records permits the detection of nonlinearities which are comparable to the noise in magnitude. Detection of such errors is a prerequisite to recalibration in software which enables error correction in remote applications, such as space power systems.

[Contact: Charles P. Fenimore, Jr., (301) 975-2428]

Fenimore, C.P., Jr., and Martzloff, F.D., Incompatibility Between the 100/1300 Surge Test and Varistor Failure Rates, Proceedings of the Ninth International Zurich Symposium and Technical Exhibition on Electromagnetic Compatibility, Zurich, Switzerland, March 12-14, 1991, pp. 525-530 (1991).

A proposed high-energy surge test featuring a $100 / 1300 \mu \mathrm{s}$ waveform and a peak voltage of 2.3 times the peak voltage of the low-frequency mains is under consideration by the IEC. The energy storage capacitor suggested for the surge generator, originally specified as high as $25000 \mu \mathrm{F}$, has been scaled down, but is still at a level of several thousand microfarads. A simple but realistic mathematical model is integrated numerically to determine the energy dissipated in such a test. The energy that would be deposited into a varistor of the voltage rating commonly used in protecting load equipment, if subjected to this test, far exceeds the capability of the varistor, but reported varistor failure rates do not reflect such a situation. Thus, a reexamination of the premises that led to the $100 / 1300-\mu$ s test specifications appears necessary.

[Contact: Charles P. Fenimore, Jr., (301) 975-2428]

\section{Magnetic Materials \& Measurements}

Cross, R.W., and Goldfarb, R.B., Hall Probe Magnetometer for SSC Magnet Cables: Effect of Transport Current on Magnetization and Flux Creep, IEEE Transactions on Magnetics, Vol. 27, No. 2, pp. 1796-1798 (March 1991).

We constructed a Hall probe magnetometer to measure the magnetization hysteresis loops of superconducting-super-collider magnet cables. The 
instrument uses two Hall-effect field sensors to measure the applied field $\mathrm{H}$ and the magnetic induction $B$. Magnetization $M$ is calculated from the difference of the two quantities. The Hall probes are centered coaxially in the bore of a superconducting solenoid with the B probe against the sample's broad surface. An alternative probe arrangement, in which $\mathrm{M}$ is measured directly, aligns the sample probe parallel to the field. We measured $\mathrm{M}$ as a function of $\mathrm{H}$ and field cycle rate both with and without a dc transport current. Flux creep as a function of current was measured from the dependence of ac loss on the cycling rate and from the decay of magnetization with time. Transport currents up to $20 \%$ of the critical current have minimal effect on magnetization and flux creep.

[Contact: R. William Cross, (303) 497-5300]

Cross, R.W., Patton, C.E., Srinivasan, G., Booth, J.G., and Chen, M., Anomalous Low Frequency Butterfly Curves for Subsidiary Absorption and FMR Overlap at $3 \mathbf{~ G H z}$, Journal of Applied Physics, Vol. 69, No. 3, pp. 1569-1573 (1 February 1991).

Subsidiary absorption butterfly curves of spin-wave instability threshold versus static in-plane field have been obtained for yttrium-iron-garnet (YIG) thin films at $3 \mathrm{GHz}$. The butterfly curves have been found to be rather anomalous, typically displaying a pronounced dip and a very low minimum threshold. These anomalous features are attributed to the overlap of the subsidiary absorption field region with ferromagnetic resonance (FMR). First-order instability theory was extended to include the uniform mode response near FMR. The extended theory yields good fits to the data for reasonable values of the YIG FMR linewidths. The theoretical analysis also shows a predicted flip in the azimuthal propagation angle $\phi_{\mathbf{k}}$ for the unstable spin waves in the region of FMR overlap. With increasing field, there are predicted discontinuous changes in $\phi_{k}$ from $90^{\circ}$ to $0^{\circ}$ and back to $90^{\circ}$ in the region of FMR.

[Contact: William R. Cross, (303) 497-5300]

Deeter, M.N., Rose, A.H., and Day, G.W., IronGarnet Magnetic Field Sensors with 100 pT/ $\sqrt{\mathrm{Hz}}$ Noise-Equivalent Field, Proceedings of the Seventh Optical Fibre Sensors Conference, Sydney, New South Wales, Australia, December 2-6, 1990, pp. 341-344 (1991).
The sensitivity of Faraday-effect sensors incorporating diamagnetically-substituted yttrium iron garnet (YIG) is potentially much higher than of sensors employing pure YIG. Results of Faraday rotation linearity and sensitivity measurements are presented for galliumsubstituted YIG. At $500 \mathrm{~Hz}$, the noise-equivalent magnetic field is approximately $100 \mathrm{pT} / \sqrt{\mathrm{Hz}}$.

[Contact: Merritt N. Deeter, (303) 497-5400]

Rice, P., and Moreland, J., A New Look at the Bitter Method of Magnetic Imaging, Review of Scientific Instruments, Vol. 62, No. 3, pp. 844-845 (March 1991).

A scanning-tunneling microscope (STM) was used in place of an optical microscope in the Bitter method to image the magnetic ferrofluid particles on the surface of a hard disk. The Bitter method is a reliable method to look at magnetic patterns on magnetic storage media. The resolution obtainable is limited by the optical viewing of the magnetic particles. Using the scanning tunneling microscope, we have obtained image resolution limited only by the ferrofluid particle size and the sharpness of the STM tip.

[Contact: Paul Rice, (303) 497-3841]

\section{Superconductors}

Beall, J.A., Cromar, M.W., Harvey, T.E., Johansson, M.E., Ono, R.H., Reintsema, C.D., Rudman, D.A., Asher, S.E., Nelson, A.J., and Swartzlander, A.B., $\mathrm{YBA}_{2} \mathbf{C U}_{3} \mathbf{0}_{7-\delta}$ /Insulator Multi-Layers for Crossover Fabrication, IEEE Transactions on Magnetics, Vol. 27, No. 2, pp. 1596-1599 (March 1991).

The development of thin-film dielectrics compatible with epitaxial growth of $\mathrm{YBa}_{2} \mathrm{Cu}_{3} \mathrm{O}_{7-\delta}$ (YBCO) is crucial to the fabrication of multilayer device and circuit structures. We have investigated the YBCO/SrTi0 3 (STO) system by fabricating YBCO/STO bilayers and simple YBCO/STO/YBCO crossover structures. The thin films were deposited in situ by pulsed laser deposition and analyzed using X-ray diffraction and scanning electron microscopy. The film interfaces were characterized by secondary-ion-mass spectroscopy depth profiling. We have developed photolithographic and wet-etching processes for patterning the crossovers which are compatible with these materials. The crossover structures were characterized by resistance and insulator pinhole density as well as the superconducting properties of 
the patterned top and bottom YBCO electrodes (critical temperature, $\mathrm{T}_{\mathrm{c}}$ and critical current density, $\mathrm{J}_{c}$ ). Using $\mathrm{SrTiO}_{3}$ as the insulating layer, we have made crossovers with good isolation between layers $\left(>100 \mathrm{M} \Omega\right.$ ) and high $\mathrm{J}_{\mathrm{c}}$ even in the top electrode $\left(\mathrm{J}_{\mathrm{c}}(76) \mathrm{K}>10^{5} \mathrm{~A} / \mathrm{cm}^{2}\right)$.

[Contact: James A. Beall, (303) 497-5989]

Cross, R.W., and Goldfarb, R.B., Enhanced Flux Creep in Nb-Ti Superconductors After an Increase in Temperature, Applied Physics Letters, Vol. 58, No. 4, pp. 415-416 (28 January 1991).

The magnetic fields of superconducting-super-collider (SSC) dipole magnets change with time when the magnets are operated at constant current. The decay of the field is thought to be a consequence of flux creep in the $\mathrm{Nb}$-Ti filaments in the superconducting cables. However, measured magnetic relaxation of small samples of SSC cable as a function of time is unlike the large decays that are observed in the fields of the actual magnets. We have made relaxation measurements on sample SSC conductors at 3.5 and 4.0 $\mathrm{K}$ after field cycling. The decay at both temperatures was $2.8 \%$ in $50 \mathrm{~min}$. However, the relaxation measured after a temperature increase from 3.5 to $4.0 \mathrm{~K}$ was $4.8 \%$ in $50 \mathrm{~min}$. A likely reason for the greater magnetization decay is that, after an increase in temperature, the $\mathrm{Nb}-\mathrm{Ti}$ is in a supercritical state, with shielding currents flowing at a density greater than the new critical current density. This causes enhanced flux creep. We suggest that a small temperature rise during the operation of SSC magnets may contribute to the unexpectedly large magnetic field decay.

[Contact: R. William Cross, (303) 497-5300]

Cross, R.W., and Goldfarb, R.B., Hall Probe Magnetometer for SSC Magnet Cables: Effect of Transport Current on Magnetization and Flux Creep, IEEE Transactions on Magnetics, Vol. 27, No. 2, pp. 1796-1798 (March 1991).

We constructed a Hall probe magnetometer to measure the magnetization hysteresis loops of superconducting-super-collider magnet cables. The instrument uses two Hall-effect field sensors to measure the applied field $\mathrm{H}$ and the magnetic induction $\mathrm{B}$. Magnetization $\mathrm{M}$ is calculated from the difference of the two quantities. The Hall probes are centered coaxially in the bore of a superconducting solenoid with the B probe against the sample's broad surface. An alternative probe arrangement, in which $M$ is measured directly, aligns the sample probe parallel to the field. We measured $\mathrm{M}$ as a function of $\mathrm{H}$ and field cycle rate both with and without a dc transport current. Flux creep as a function of current was measured from the dependence of ac loss on the cycling rate and from the decay of magnetization with time. Transport currents up to $20 \%$ of the critical current have minimal effect on magnetization and flux creep.

[Contact: R. William Cross, (303) 497-5300]

Ekin, J.W., Salama, K, and Selvamanickam, V., Current Record in Superconductors, Nature, Vol. 350, p. 26 (7 March 1991).

We report the first direct demonstration that high transport $J_{c}$ can be achieved in bulk melt-grown $\mathrm{YBa}_{2} \mathrm{Cu}_{3} \mathrm{O}_{7}$ at magnetic fields up to $30 \mathrm{~T}$ at liquid nitrogen temperature.

[Contact: John W. Ekin, (303) 497-5448]

Goodrich, L.F., Moreland, J., and Roshko, A. Switching in High- $T_{c}$ Superconductor Current Transport Measurements, IEEE Transactions on Magnetics, Vol. 27, No. 2, pp. 1194-1197 (March 1991).

Switching voltages can occur in four wire current transport measurements of sintered high- $T_{c}$ superconductors. These switching voltages are irreversible shifts in the voltage-current characteristic of the superconductor that result in multiple branches of the voltage-current characteristic. The voltage along these branches can be very nonlinear with respect to current and can be positive or negative in polarity relative to the current direction. These voltages can interfere with the correct determination of resistivity and critical current density. Experimental data on nonaligned sintered high- $T_{c}$ materials are presented which illustrate the complex nature of the voltages and the confusion they can create. Models based on weak links and $\mathrm{H}_{\mathrm{cl}}$ and other effects are discussed along with observations in conventional (low $T_{c}$ ) superconductors.

[Contact: Loren F. Goodrich, (303) 497-3143]

Moreland, J., and Rice, P., Tunneling Stabilized Magnetic Force Microscopy: Prospects for Low Temperature Applications to Superconductors, 
IEEE Transactions on Magnetics, Vol. 27, No. 2, pp. 1198-1201 (March 1991).

We have recently demonstrated an imaging technique referred to as tunneling stabilized magnetic force microscopy (TSMFM). TSMFM is performed using a scanning tunneling microscope (STM) with a flexible, magnetic, tunneling tip in place of the usual rigid tunneling tip. TSMFM images are therefore combinations of topography and the magnetic forces between the tip and the sample. Room-temperature TSMFM images of bit tracks on a hard disk have $100-\mathrm{nm}$ resolution and are comparable to Bitter patterns made using a ferrofluid. We are presently building a lowtemperature STM for TSMFM of the flux lattice in superconductors. Design and testing of the apparatus are discussed along with preliminary results.

[Contact: John Moreland, (303) 497-3641]

Petersen, T.W., and Goldfarb, R.B., Effect of Mechanical Deformation on Nb-Ti Filament Proximity-Effect Coupling at the Edges of SSC Cables, IEEE Transactions on Magnetics, Vol. 27, No. 2, pp. 1809-1810 (March 1991).

Magnetization as functions of transverse magnetic field and time was measured for short strands extracted from the centers and edges of five $\mathrm{Nb}$ - $\mathrm{Ti}$ Rutherford cables designed for use in superconducting-supercollider dipole magnets. The strands all had $6-\mu \mathrm{m}$ diameter filaments. Edge samples, which had severe mechanical deformation, showed small magnetic coupling losses at low fields, compared to no coupling losses for undeformed center strands. This suggests that the cabling process decreases the interfilament spacing to the order of the coherence length in the normal matrix material, resulting in an increase in effective filament diameter and hysteresis loss at low fields. Microscopic studies of the cables' cross sections confirmed smaller interfilament separations in these samples. Flux creep measurements, represented by the time dependence of magnetization, showed little difference between edge and center samples. This indicates that the proximity-coupled matrix in edge samples is not a significant source of flux creep.

[Contact: Timothy W. Petersen, (303) 497-5333]

Roshko, A., Ono, R.H., Beall, J.A., Moreland, J., Nelson, A.J., and Asher, S.E., Morphology of Silver on $\mathrm{YBa}_{2} \mathrm{Cu}_{3} \mathrm{O}_{7-\delta}$ Thin Films, IEEE Transactions on Magnetics, Vol. 27, No. 2, pp. 1616-1618 (March
1991).

The morphology of silver layers deposited and annealed on laser ablated YBCO films has been examined as a function of the microstructure of the $\mathrm{YBa}_{2} \mathrm{Cu}_{3} \mathrm{O}_{7-\delta}$ film, the thickness of the Ag layer, and the anneal time, temperature, and atmosphere. The most important parameter for maintaining uniform silver coverage during anneals is the thickness of the silver layer. For thin silver films, it may be possible to prevent dewetting of the YBCO by using short anneals at low temperatures.

[Contact: Alexana Roshko, (303) 497-5420]

Russek, S.E., Jeanneret, B., Rudman, D. A, and Ekin, J.W., Properties of $\mathrm{YBa}_{2} \mathrm{Cu}_{3} \mathrm{O}_{7-\delta}$ Thin Films Grown on Off-Axis-Cut MgO Substrates, IEEE Transactions on Magnetics, Vol. 27, No. 2, pp. 931. 934 (March 1991).

A series of $\mathrm{YBa}_{2} \mathrm{Cu}_{3} \mathrm{O}_{7-\delta}$ films has been reactively sputtered on off-axis-cut $\mathrm{MgO}$ substrates. All the films were oriented with the c-axis normal to the substrate regardless of substrate orientation, indicating that growth dynamics is a major factor influencing film orientation on non-lattice matched substrates. As the substrate orientation is moved off the (100) direction, the films showed a decrease in transition temperature and showed properties indicative of an increased density of weak links. On high-angle substrates, the films showed improved properties over the films on low-angle substrates. Films grown on (110) $\mathrm{MgO}$ were as good as films grown on (100) $\mathrm{MgO}$.

[Contact: Steven E. Russek, (303) 497-5097]

\section{ELECTROMAGNETIC INTERFERENCE}

\section{Conducted EMI}

Fenimore, C.P., Jr., and Martzloff, F.D., Incompatibility Between the 100/1300 Surge Test and Varistor Failure Rates, Proceedings of the Ninth International Zurich Symposium and Technical Exhibition on Electromagnetic Compatibility, Zurich, Switzerland, March 12-14, 1991, pp. 525-530 (1991).

A proposed high-energy surge test featuring a $100 / 1300-\mu$ s waveform and a peak voltage of 2.3 times the peak voltage of the low-frequency mains is under consideration by the IEC. The energy storage capacitor suggested for the surge generator, originally 
specified as high as $25000 \mu \mathrm{F}$, has been scaled down but is still at a level of several thousand microfarads. A simple but realistic mathematical model is integrated numerically to determine the energy dissipated in such a test. The energy that would be deposited into a varistor of the voltage rating commonly used in protecting load equipment, if subjected to this test, far exceeds the capability of the varistor, but reported varistor failure rates do not reflect such a situation. Thus, a reexamination of the premises that led to the $100 / 1300$ - $\mu$ s test specifications appears necessary.

[Contact: Charles P. Fenimore, Jr., (301) 975-2428]

Martzloff, F.D., and Pellegrini, G., Real, Realistic Ring Waves for Surge Testing, Proceedings of the Ninth International Zurich Symposium and Technical Exhibition on Electromagnetic Compatibility, Zurich, Switzerland, March 12-14, 1991, pp. $499-504$ (1991).

Five independent investigations on the coupling of surges into low-voltage circuits (data or power lines), and of their effects, show that a damped oscillatory transient is a real, realistic stress for equipment connected to these lines.

[Contact: Francois D. Martzloff, (301) 975-2409]

\section{Radiated EMI}

Adams, J. W., Status Report on Shielding Effectiveness Measurements: Release of ASTM Standard D4935-89, Proceedings of the Fourth International Society for the Advancement of Material and Process Engineering (SAMPE) Conference, Albuquerque, New Mexico, June 13, 1990, pp. 1-9 (1991).

ASTM (formerly the American Society of Testing and Materials) released Standard D4935-89, Standard Test Method for Measuring the Electromagnetic Shielding Effectiveness of Planar Materials, in November 1989. Some background efforts of ASTM Committee D.09.12.14 to accomplish this are reviewed, with emphasis on results of the measurement round robins that led to the acceptance of the standard in April of 1989. Very good agreement was obtained during these round robins conducted by five different workers at five different organizations. The samples used were plastic based, but treated three different ways. Surface roughness of the sample is an important factor in determining measurement uncertainty. The design of the sample holder and the measurement procedure given in this ASTM standard were developed at the National Institute of Standards and Technology (NIST). The comprehensive effort at NIST also established why this measurement method was chosen over numerous others. How and when calculations can be used to obtain near-field data from the measured far-field data are covered.

[Contact: John W. Adams, (303) 497-3328]

Camell, D.G., Larsen, E.B., Cruz, J.E., and Hill, D.A., NIST Calibration Procedure for Vertically Polarized Monopole Antennas, $30 \mathrm{kHz}$ to $300 \mathrm{MHz}$, NIST Technical Note 1347 (January 1991).

This report describes the theoretical basis and test procedure for vertically polarized monopole antenna calibrations at the National Institute of Standards and Technology (NIST). The standard field method applies the theoretical equations of a vertical monopole antenna to calculate the vertical electric field. This method is used at the NIST open-field site in the frequency range of $30 \mathrm{kHz}$ to $300 \mathrm{MHz}$. The uncertainty in the antenna factor of the antenna under test (AUT) is now $\pm 1 \mathrm{~dB}$.

[Contact: Dennis G. Camell, (303) 497-3214]

Hill, D.A. A Generalization of the Cornu Spiral for Lossy Media, Journal of Applied Physics, Vol. 69, No. 3, pp. 1772-1774 (1 February 1991).

The classical problem of Fresnel diffraction by a straightedge is extended to allow for loss in the medium. The loss modifies the usual Cornu spiral solution because the argument of the Fresnel integral becomes complex. For high loss the contributions of the outer Fresnel zones are highly attenuated.

[Contact: David A. Hill, (303) 497-3472]

Kanda, M., and Randa, J., Estimation of Electromagnetic Fields in Complex Environments [original title: Possible Estimation Methodologies for Electromagnetic Field Distributions in Complex Environments], Proceedings of the Ninth International Zurich Symposium and Technical Exhibition on Electromagnetic Compatibility, Zurich, Switzerland, March 12-14, 1991, pp. 337-342 (1991).

The problem of measuring and characterizing complicated multiple-source, multiple-frequency electromagnetic environments is becoming more important and more difficult as electrical devices 
proliferate. This paper reviews three general approaches to the problem which have been investigated at the National Institute of Standards and Technology. The three approaches are: 1) a statistical treatment of the spatial distribution of electromagnetic field intensities, 2) a numerical computation using a finite-element (or lattice) form of the electromagnetic action functional, and 3 ) use of a directional probe to scan a volume. All three methods are still in the development stage, but each appears promising.

[Contact: Motohisa Kanda, (303) 497-5320]

Randa, J.P., Simultaneous vs. Independent Injection Testing of Nonlinear Multiport Systems, Proceedings of the Ninth International Zurich Symposium and Technical Exhibition on Electromagnetic Compatibility, Zurich, Switzerland, March 12-14, 1991, pp. $71-74$ (1991).

This paper is a theoretical investigation of the question whether, in injection testing of a multiport system, all ports must be injected and tested simultaneously. A general, nonlinear, three-port system is analyzed. Conditions under which the ports can be tested separately are derived, and problems with the practical application of these conditions are pointed out. Systems with memory are also treated, and the extension to general multiports is given. The relevance to bulk injection testing is discussed.

[Contact: James P. Randa, (303) 497-3150]

Wilson, P.F., and Ma, M.T., Fields Radiated by Electrostatic Discharges, IEEE Transactions on Electromagnetic Compatibility, Vol. 33, No. 1, pp. 10-18 (February 1991).

Electrostatic discharge (ESD) metrology has, to date, primarily focused on the ESD current waveforms in order to develop simulators for susceptibility testing. Significantly less attention has been given to the fields generated by an ESD event. This paper examines ESD fields both analytically and experimentally. Measurements indicate that the electric fields can be quite significant ( $\geq 150 \mathrm{~V} / \mathrm{m}$ at a distance of $1.5 \mathrm{~m}$, for example) for short periods of time (a few nanoseconds), particularly for relatively low-voltage events $(\leq 6 \mathrm{kV})$. A relatively simple dipole model of an ESD spark is developed and used to predict the radiated fields. The agreement between theory and experiment is fair. The model may be used to predict ESD fields for a wide range of possible configurations, particularly in the near-field zone where no measurements are presently available.

[Contact: Mark T. Ma, (303) 497-3800]

\section{ADDITIONAL INFORMATION}

\section{Lists of Publications}

DeWeese, M.E., Metrology for Electromagnetic Technology: A Bibliography of NIST Publications, NISTIR 3946 (August 1990).

This bibliography lists the publications of the personnel of the Electromagnetic Technology Division of NIST in the period from January 1970 through publication of this report. A few earlier references that are directly related to the present work of the Division are included.

[Contact: Sarabeth Moynihan, (303) 497-3678]

Lyons, R.M., and Gibson, K.A., A Bibliography of the NIST Electromagnetic Fields Division Publications, NISTIR 3945 (August 1990).

This bibliography lists publications by the staff of the National Institute of Standards and Technology's Electromagnetic Fields Division for the period from January 1970 through August 1990. Selected earlier publications from the Division's predecessor organizations are included.

[Contact: Kathryn A. Gibson, (303) 497-3132]

Palla, J.C., and Meiselman, Bo, Electrical and Electronic Metrology: A Bibliography of NIST Electricity Division's Publications, NIST List of Publications 94 (January 1991).

This bibliography covers publications of the Electricity Division, Center for Electronics and Electrical Engineering, NIST, and of its predecessor sections for the period January 1968 to December 1990. A brief description of the Division's technical program is given in the introduction.

[Contact: Jenny C. Palla, (301) 975-2220]

Walters, E.J., Semiconductor Measurement Technology, NIST List of Publications 72 [a bibliography of NIST publications concerning semi- 
conductor measurement technology for the years 1962 1989] (March 1990), and LP72 Supplement, Publications for the Year 1990 (April 1991).

The bibliography contains reports of work performed at the National Institute of Standards and Technology in the field of Semiconductor Measurement Technology in the period from 1962 through December 1990. An index by topic area and a list of authors are provided. The supplement provides information on technology transfer at NIST for calendar year 1990, not only from those groups specializing in semiconductor electronics, but also including NIST-wide research now coordinated by the NIST Office of Microelectronics Programs.

[Contact: E. Jane Walters, (301) 975-2050]

\section{New NIST Research Material}

NIST has announced the availability of Research Material 8458, a well-characterized artificial flaw used as an artifact standard in eddy current nondestructive evaluation (NDE). The new Research Material (RM) is the outcome of work carried out by the Electromagnetic Technology Division to address the need for calibration standards for eddy-current NDE, for example, as used to detect fatigue cracks in aircraft structures. The RM flaw is produced in an annealed aluminum alloy block by first indenting the block and then compressively deforming the resulting notch until it is tightly closed. The next operation is to restore a flat finish to the block face, after which the block is heat treated to the original temper. The controlled flaw has been named the "CDF notch," after its inventors (listed on patent application) Thomas E. Capobianco (Electromagnetic Technology Division), William P. Dube (Division 832), and Ken Fizer (Naval Aviation Depot, NAS Norfolk, Virginia).

In the past, the challenge has been to manufacture artificial flaws that closely simulate the mechanical properties of fatigue cracks. Currently used artifacts include electrical-discharge-machined and saw-cut notches, both of which are relatively poor representations of fatigue cracks as their widths are too great. The Division-developed method provides notches that can be made controllably in a variety of geometries, have known dimensions, with widths that are narrow enough to provide an acceptable representation of fatigue cracks.
An NIST Research Material is not certified by NIST, but meets the International Standards Organization definition of "a material or substance one or more properties of which are sufficiently well established to be used in the calibration of an apparatus, the assessment of a measurement method, or for assigning values to materials." The documentation issued with RM 8458 is a "Report of Investigation." Contact: technical information - Fred Fickett, (303) 497-3785; order information - Standard Reference Materials Program, (301) 975-6776.

Emerging Technologies in Electronics ... and Their Measurement Needs, Second Edition

This report assesses the principal measurement needs that must be met to improve U.S. competitiveness in emerging technologies within several fields of electronics: semiconductors, superconductors, magnetics, optical fiber communications, optical fiber sensors, lasers, microwaves, video, and electromagnetic compatibility. The report seeks feedback from industry and Government agencies on the assessment. The feedback will guide the development of NIST programs that provide U.S. industry with new documented measurement methods, new national reference standards to assure the accuracy of those measurement methods, and new reference data for electronic materials. Copies may be obtained by ordering Report No. PB90-188087/AS (\$23.00 hard copy, $\$ 11.00$ microfiche) from the National Technical Information Service, 5285 Port Royal Road, Springfield, VA 22161, (703) 487-4650.

\section{EEEL CALENDAR}

September 29 and October 1-2, 1991 (Scottsdale, AZ)

11th VLSI and GaAs Packaging Workshop. This 11th annual workshop is co-sponsored by the IEEE CHMT Society and the National Institute of Standards and Technology. Topics to be discussed include: VLSI package design, integrated package design, multichip module design, package thermal and electrical design, GaAs IC packaging, VLSI package interconnection options, VLSI package materials and die-attach solutions, and failure mechanism and quality of VLSI packages. Contact: George G. Harman, (301) 975 2097. 


\section{EEEL SPONSORS}

National Institute of Standards and Technology

U.S. Air Force

McClelland Air Force Base; Newark Air Force

Station; Space \& Missile Organization;

Wright-Patterson Air Force Base; Secretary of the Air Force Headquarters, Office of Research

U.S. Army

Fort Belvoir; Fort Huachuca; Harry Diamond Laboratory; Materials \& Mechanics Research Center; Redstone Arsenal; Strategic Defense Command; Dugway Proving Ground; The Pentagon

Department of Commerce

NOAA

Department of Defense Advanced Research Projects Agency; Defense Nuclear Agency; Combined Army/Navy/Air Force (CCG)

Department of Energy

Energy Systems Research; Fusion Energy; Basic Energy Sciences; High Energy \& Nuclear Physics
Department of Justice

Law Enforcement Assistance Administration

U.S. Navy

David Taylor Research Center; Naval Sea Systems Command; Weapons Support Center/Crane; Office of Naval Research; Naval Ship Research Development Center; Naval Air Systems Command; Naval Air Engineering Center; Aviation Logistics Center/Patuxent; Naval Explosive Ordnance Disposal Tech. Center; Naval Research Laboratory, Naval Aviation Depot, Naval Ocean Systems, Center

National Science Foundation

National Aeronautics and Space Administration NASA Headquarters; Goddard Space Flight

Center; Lewis Research Center

Nuclear Regulatory Commission

Department of Transportation

National Highway Traffic Safety Administration

MIMIC Consortium

Various Federal Government Agenices 



\section{BIBLIOGRAPHIC DATA SHEET}

2. PERFORMING ORGANIZATION REPORT MUMBER

3. PUBUCATION DATE

September 1991

4. TITLE AND SUBTITLE

Electronics and Electrical Engineering Laboratory Technical Publication Announcements Covering Laboratory Programs, January to March 1991, with 1991 EEEL Events Calendar

5. AUTHOR(S)

J. A. Gonzalez, compiler

6. PERFORMINQ ORGANIZATION (IF JOINT OR OTHER THAN NIST, SEE INSTRUCTIONS)

U.S. DEPARTMENT OF COMMERCE

MATIONAL INSTITUTE OF STANDARDS AND TECHNOLOQY

GAITHERSBURG, MO 20890

9. SPONSORING ORGANIZATION MAME AND COMPLETE ADDRESS (STREET, CITY, STATE, ZIP)

7. CONTRACT/GRANT NUMBER

8. TYPE OF REPORT AND PERIOD COVERED

January-March 1991

\section{U.S. Department of Commerce}

National Institute of Standards and Technology

Electronics and Electrical Engineering Laboratory

10. SUPPLEMENTARY NOTES

11. ABSTRACT (A 200-WORD OA LESS FACTUAL SUMMAAY OF MOST SIONIFICANT INFORMATION. IF DOCUMENT INCLUDES A SIONIFICANT BIBLOORAPHY OR UTERATURE SURVEY, MENTION IT HERE,

This is the twenty-eighth issue of a quarterly publication providing information on the technical work of the National Institute of Standards and Technology, Electronics and Electrical Engineering Laboratory. This issue of the EEEL Technical Publication Announcements covers the first quarter of calendar year 1991. Abstracts are provided by technical area for papers published this quarter.

antennas; electrical engineering; electrical power; electromagnetic interference; electronics; instrumentation; laser; magnetics; microwave; optical fibers; semiconductors; superconductors 


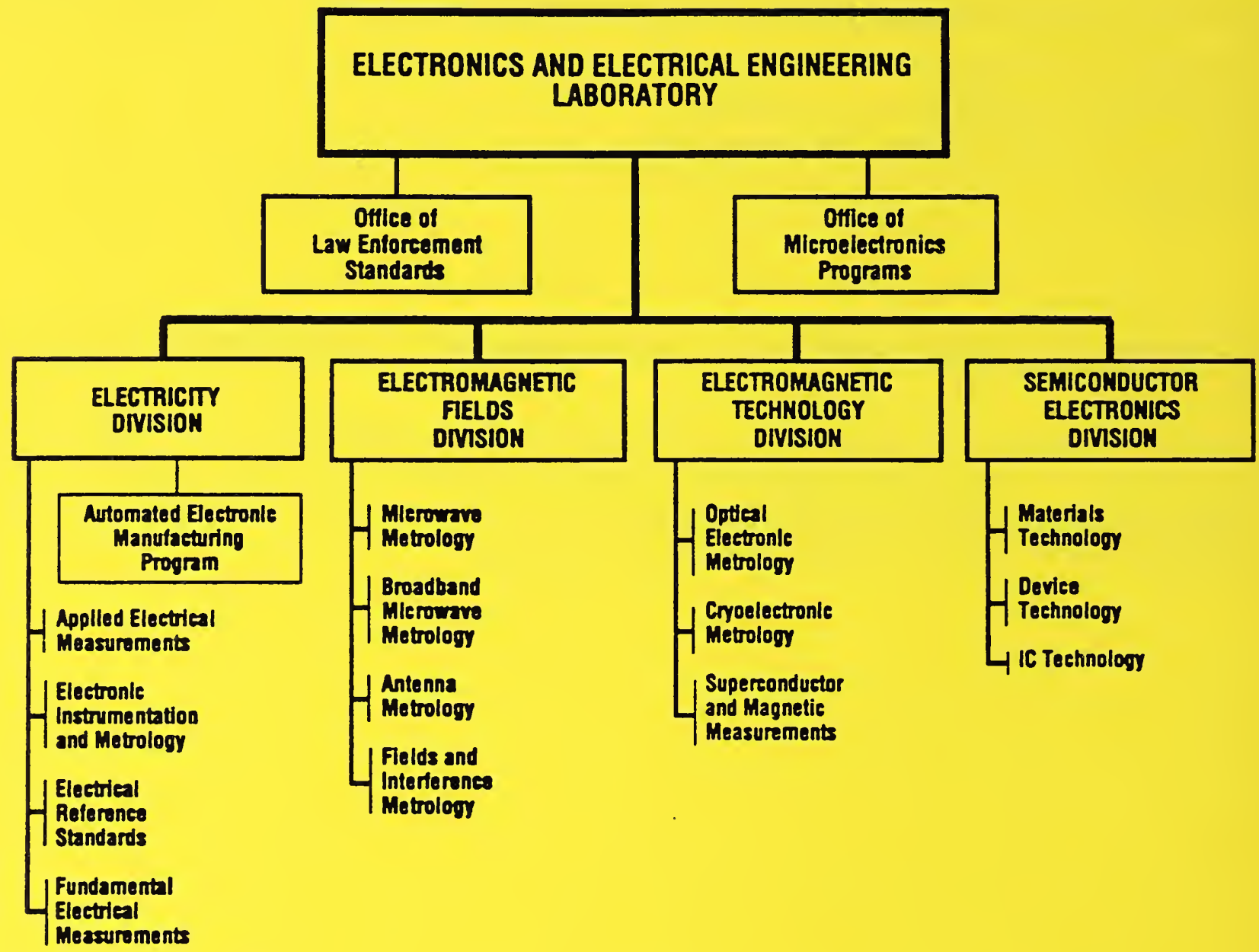

\section{KEY CONTACTS}

Laboratory Headquarters (810)

Office of Microelectronics Programs Office of Law Enforcement Standards Electricity Division (811)

Semiconductor Electronics Division (812)

Electromagnetic Fields Division (813)

Electromagnetic Technology Division (814)
Director, Mr. Judson C. French (301) 975-2220 Deputy Director, Or. Robert E. Hebner (301) 975-2220

Director, Mr. Robert I. Scace (301) $975-4400$

Director, Mr. Lawrence K Eliason (301) 975-2757

Chief, Dr. Oskars Petersons (301) 975-2400

Chief, Mr. Frank F. Oettinger (301) 975-2054

Chief, Dr. Ramon C. Baird (303) 497,3131

Chief, Dr. Robert A. Kamper (303) 4973535

\section{INFORMATION:}

For additional information on the Electronics and Electrical Engineering Laboratory, wrtte or call: Electronlcs and Electrical Englneering Laboratory Natlonal Institute of Standards and Technology Metrology Bullding, Room B-358 